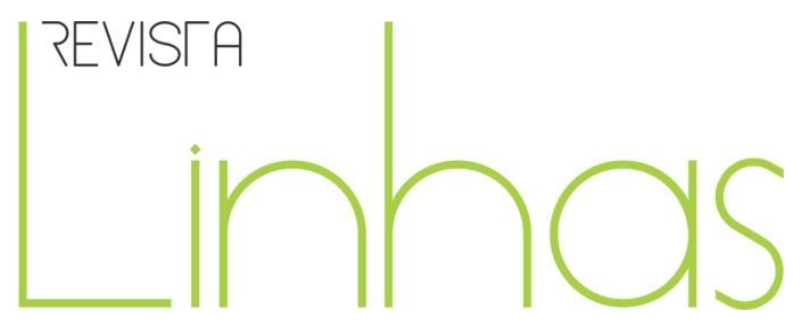

\title{
O Parfor como processo de formação inicial de professores para a educação básica no Brasil
}

\section{Resumo}

O artigo apresenta um estudo sobre programas fomentados pela Capes para a formação de professores, em especial o Plano Nacional de Formação de Professores da Educação Básica (Parfor), uma política pública educacional voltada para a formação inicial de professores, no período de 2007 a 2016. O objetivo foi conhecer e analisar o contexto dessa formação e compreender como ela é realizada. A partir do conceito de políticas públicas e formação de professores, embasado em Dourado (2015), Tardif (2014), Souza (2014) e Ghedin, Almeida e Leite (2008), foi feita a análise do contexto entre o que dizem os autores e o que está sendo realizado, no que tange às políticas públicas voltadas para programas de formação inicial e continuada de professores no Brasil, estando entre essas a formação inicial pelo Parfor. A metodologia da pesquisa se caracteriza como qualitativa, teve como corpus de análise documentos disponibilizados em sites oficiais e no Portal da Capes e os relatórios de prestação de contas de 16 Instituições de Ensino Superior, os quais possibilitaram conhecer os programas da Capes, suas finalidades, o público envolvido e possíveis efeitos para a Educação Básica e vislumbrar, no caso do Parfor, um panorama sobre a conexão entre teoria e prática docente, como parte de um conjunto de políticas envolvendo a formação de professores. Os principais resultados apontam para a análise dos referidos relatórios, que procurou ver como as IES organizaram os cursos e quais resultados apontaram sobre o aprimoramento da prática docente.

Palavras-chave: Professores - Formação. Educação e Estado - Brasil. Educação de base.
Frederico Batista Nepomuceno

Universidade Federal do Rio Grande do Sul - UFRGS - Porto Alegre/RS Brasil freddbass@gmail.com

\section{Para citar este artigo:}

NEPOMUCENO, Frederico Batista. O Parfor como processo de formação inicial de professores para a educação básica no Brasil. Revista Linhas. Florianópolis, v. 21, n. 46, p. 304-332, maio/ago. 2020. 


\title{
Parfor as a process of initial teacher training for basic education in Brazil
}

\begin{abstract}
The article presents a study about programs promoted by Capes for teacher training, especially the National Plan for the Training of Basic Education Teachers (Parfor), an educational public policy focused on initial teacher education, from 2007 to 2016. The objective was to know and analyze the context of this formation and to understand how it is realized. Based on the concept of public policies and teacher training, based on Dourado (2015), Tardif (2014), Souza (2014) and Ghedin, Almeida and Leite (2008), the context was analyzed, authors and what is being done, with regard to public policies focused on initial and continuing teacher training programs in Brazil, including Parfor's initial training. The methodology of the research is characterized as qualitative, had as a corpus of analysis documents made available on official websites and in the Portal of Capes and the reports of accountability of 16 Institutions of Higher Education, which made it possible to know Capes' programs, its purposes, the public involved and possible effects on Basic Education and to envisage in Parfor's case an overview of the connection between theory and teaching practice as part of a set of policies involving teacher training. The main results point to the analysis of these reports, which sought to see how the universities organized the courses and what results pointed to the improvement of teaching practice.
\end{abstract}

Keywords: Teachers - Training. Education and State Brazil. Basic education. 
Desde a promulgação da última LDB (BRASIL, 1996), mudanças significativas têm sido anunciadas no campo da educação, mobilizando políticas públicas como reformas curriculares na Educação Básica e em cursos de formação de professores.

No ano de 2007, a Coordenação de Aperfeiçoamento de Pessoal de Nível Superior (Capes), uma Fundação Pública que desde a sua criação atua na modalidade stricto sensu, passou a atuar também no fomento de políticas públicas para a formação inicial e continuada de professores para a Educação Básica. Dentro desse contexto, a Capes criou o Plano Nacional de Formação de Professores da Educação Básica (Parfor), desenvolvido, inicialmente, nas modalidades presencial e a distância, sendo responsável pelo Parfor na modalidade presencial, a Diretoria de Educação Básica (DEB), e pelo Parfor na modalidade a distância, a Diretoria de Educação a Distância (DED).

O Parfor foi criado como programa emergencial para atender o disposto no artigo 11, inciso III do Decreto $n^{\circ}$ 6.755, de 29 de janeiro de 2009 (BRASIL, 2009a), que institui a Política Nacional de Formação de Profissionais do Magistério da Educação Básica, disciplinando a atuação da Capes no fomento a programas de formação inicial e continuada. Tal programa visou atender as diretrizes ancoradas no Plano de Metas Compromisso Todos pela Educação, criado pelo Decreto $n^{\circ}$ 6.094/2007, como programa estratégico do Plano de Desenvolvimento da Educação (PDE). Esse Plano, lançado em 2007, elencava entre seus objetivos, a formação de professores e a valorização dos profissionais da educação (BRASIL, 2007).

Como já dito, desde a promulgação da LDB/1996, tem sido recorrente a implementação de políticas públicas para a melhoria da Educação Básica, implicando em políticas para a formação de professores com investimentos que, no caso da Capes, apenas no ano de 2016, foram de $\mathrm{R} \$ \mathbf{8 6 8 . 5 5 5 . 2 3 4}$ (oitocentos e sessenta e oito milhões, quinhentos e cinquenta e cinco mil, duzentos e trinta e quatro reais), para o fomento de bolsa de estudos. No mesmo período, o valor da dotação orçamentária para fomentar as

\footnotetext{
${ }^{1}$ Informamos que o referido artigo se trata de uma adaptação da minha tese de doutorado intitulada "O Plano Nacional de Formação de Professores da Educação Básica (Parfor) como Política da Capes para a Formação de Professores", defendida em 25/03/2019.
} 
ações de formação de professores para a Educação Básica, foi de R\$ 195.014.194 (cento e noventa e cinco milhões, quatorze mil e cento e noventa e quatro reais $)^{2}$.

Segundo o documento disponível no site da Capes, esses investimentos são voltados para a melhoria da formação de professores, de condições pedagógicas e de recursos para o ensino em um país com disparidades regionais imensas, com estados que dispõem de condições melhores do que outros, tanto em relação à estrutura das escolas, quanto com relação à titulação do corpo docente. Melhorar a formação de professores para atender as diferentes áreas de conhecimento, em especial a área de ciências, é necessário e urgente, uma vez que a falta de professores tem causado lacunas na formação dos alunos, seja pela falta de profissionais nas escolas, seja pela falta de formação de professores para as áreas nas quais atuam.

Sabe-se que os problemas que estão sendo apontados têm efeitos no desempenho dos alunos, implicando em altas taxas de desistência e de reprovação o que, por sua vez, causa desmotivação nos professores. Enfim, há uma série de problemas que, de certo modo, impelem ações de órgãos governamentais, o que justifica ações como a da Capes em relação ao financiamento do programa Parfor.

O artigo que estamos apresentando se refere a uma pesquisa sobre programas fomentados pela Capes, para a formação de professores, em especial o Parfor, uma política pública educacional voltada para a formação inicial de professores. Analisar o contexto dessa formação e compreender como ela é realizada, constitui um trabalho investigativo que poderá auxiliar profissionais que atuam na área de educação, na proposição e avaliação de políticas públicas de formação de professores para a Educação Básica, no ensino superior e, também, em cursos em nível de mestrado e doutorado que desenvolvem ações para a formação docente.

A partir dessas considerações, passamos a apresentar um estudo acerca das políticas de formação de professores, no período de 2007 a 2016, visando mostrar o contexto brasileiro de produção de programas para a formação docente, em especial o Programa Parfor. A pesquisa, realizada com documentos disponibilizados em sites

\footnotetext{
${ }^{2}$ Disponível em < http://www.capes.gov.br/images/stories/download/diversos/02052017-ORCAMENTO-PORPPA-2004-2019.pdf>. Acesso em: 30 out. 2017.
} 
oficiais, como o Portal da Capes 3 , do Governo Federal ${ }^{4}$ e especialmente nos relatórios de prestação de contas das 16 IES, possibilitou a obtenção de informações sobre as práticas adotadas na execução do Parfor, suas finalidades, o público envolvido e possíveis efeitos para a Educação Básica.

\section{Políticas para formação de professores}

No âmbito da Capes, às políticas públicas educacionais têm sido delegadas a função de organizar, orientar e normatizar a educação em diferentes níveis e dimensões, estando entre suas ações a promoção de políticas para a formação de professores, questão recorrentemente apontada como causa e, ao mesmo tempo, como solução para os problemas na educação. Os programas de formação de professores mobilizam planos, currículos, projetos educacionais, etc., e, mesmo que suas ações ocorram em diferentes direções, consideram o professor peça chave para o sucesso da educação básica brasileira.

Pereira (2006, p. 54), pesquisador da área de formação de professores, ao traçar um breve histórico sobre as licenciaturas no Brasil, indica que essas foram criadas nos anos de 1930, nas antigas Faculdades de Filosofia, como consequência da preocupação com a regulamentação do preparo de docentes para a escola secundária. De acordo com esse autor, durante muito tempo os cursos de licenciatura seguiram a fórmula " $3+1$ ", com as disciplinas de conteúdos específicos das áreas de formação sendo cursadas nos três primeiros anos do curso, e as disciplinas de natureza pedagógica cursadas em um ano, ao final do curso.

A partir dos anos de 2000, em função das orientações de Diretrizes Curriculares Nacionais para a Formação de Professores, houve a reestruturação dos cursos de licenciatura, sendo uma das justificativas para tais mudanças, a necessidade de ter uma identidade própria que os desvinculasse dos cursos de bacharelado. Mas o movimento pela reformulação dos cursos de formação de educadores no Brasil iniciou bem antes, ainda no final da década de 70, em discussões e reflexões nos cursos de Pedagogia, sendo, posteriormente, estendidas aos cursos de licenciatura, de modo geral. Esse

\footnotetext{
3 Disponível em <http://www.capes.gov.br/educacao-basica>. Acesso em: 10 nov. 2017.

${ }^{4}$ Disponível em <http://www4.planalto.gov.br/legislacao>. Acesso em: 12 nov. 2017.
} 
movimento articulou-se mais enfaticamente em 1980, com a instalação, durante a I

Conferência Brasileira de Educação, em São Paulo, do Comitê Nacional Pró Formação do Educador, representando uma oposição à Proposta Valnir Chagas, pela criação das licenciaturas de $1^{\circ}$ grau (chamadas licenciaturas “curtas"), cuja ideia era a formação de professores polivalentes (PEREIRA, 2006, p. 55).

Como se pode perceber, a preocupação com os problemas referentes à formação de professores e dos cursos de licenciatura é antiga e, mesmo que tenha sofrido mudanças, ainda hoje, permanece a intenção de melhorar a formação de professores, visando a melhoria da educação no país. Nesse sentido, Ghedin, Leite e Almeida apontam preocupações com o processo de formação inicial de professores, ressaltando que:

Vários estudos têm mostrado que os profissionais não estão sendo formados e nem estão recebendo preparo suficiente no processo inicial de sua formação docente para enfrentar a nova realidade da escola pública e as demandas hoje existentes, assumindo as novas atribuições que passam a ser cobradas dos professores. [...] a formação inicial do professor se apresenta de forma insuficiente e aligeirada, não sendo capaz de suprir os desafios da formação docente diante do novo contexto que exige dos profissionais uma série de capacidades e habilidades (pensamento sistemático, criatividade, solidariedade, habilidade de resolver problemas, trabalhos em equipe, dentre outros) que não estavam presentes nos cursos de formação. (GHEDIN; LEITE; ALMEIDA, 2008, p. 29)

Essas e outras considerações apontam para a necessidade de tratar a formação de professores como questão imperiosa, quando se trata de melhorias da educação. Com o anúncio de melhorar a formação de professores, o governo brasileiro instituiu e financiou ações envolvendo reformas curriculares em cursos de licenciatura e programas voltados para a formação inicial e continuada de professores, em parceria com instituições formadoras e a Educação Básica, como forma de preparar os professores para atender demandas de docentes em diferentes áreas do conhecimento. Sendo nesse contexto que o Parfor, como política de formação inicial de professores, foi implementado.

Para Ghedin, Leite e Almeida (2008, p. 17), os cursos de formação de professores devem possibilitar aos docentes, antes de tudo, superar o modelo de racionalidade técnica para lhes assegurar a base reflexiva na sua formação e atuação profissional, o que implica superar um modelo de formação que considera o professor como transmissor de 
conhecimentos, preocupado apenas com a formação de atitudes de obediência, de passividade e de subordinação nos alunos, que seriam vistos como assimiladores de conteúdos, a partir de práticas de memorização e repetição, sem relação com o cotidiano ou a vida social dos estudantes. Para esses autores:

É preciso assegurar que a formação de professores possibilite ao profissional docente saber lidar com o processo formativo dos alunos em suas várias dimensões, além da cognitiva, englobando a dimensão afetiva, da educação dos sentidos, da estética, da ética e dos valores emocionais. Exige ainda uma formação que promova a participação ativa do professor no projeto pedagógico da escola, em solidariedade com os colegas e como os alunos [...]. (GHEDIN; LEITE E ALMEIDA, 2008, p. 17)

Considerando que a formação de professores deve estar em conexão com as demandas da Educação Básica, na proposição do Parfor, um curso de formação inicial para professores em exercício, as instituições de ensino superior (que já realizam a formação em cursos de licenciatura) são responsáveis pelo planejamento das atividades e ações de formação dos professores que cursam o Parfor, em diferentes áreas do conhecimento e em seus contextos de atuação.

Nessa ou em qualquer outra proposta de formação inicial de professores, consideramos, tal como Tardif (2014, p. 229-230), ser “importante os professores sentirem-se sujeitos ativos no processo de exercício da docência, atores competentes e sujeitos do conhecimento", o que implica deixar de considerar os professores apenas como técnicos que aplicam conhecimentos produzidos por outros (pelos pesquisadores universitários ou peritos em currículo ou, ainda, funcionários do Ministério da Educação, por exemplo). Para esse autor,

Um professor de profissão não é somente alguém que aplica conhecimentos produzidos por outros, não é somente um agente determinado por mecanismos sociais: é um ator no sentido forte do termo, isto é, um sujeito que assume sua prática a partir dos significados que ele mesmo lhe dá, um sujeito que possui conhecimentos e um saberfazer provenientes de sua própria atividade e a partir dos quais ele a estrutura e a orienta. (TARDIF, 2014, p. 229-230)

Sob essa perspectiva, o professor torna-se sujeito ativo do seu processo de formação, em relação a sua prática cotidiana, com possibilidade de rever essa prática na 
escola. Para Tardif (2014), é importante considerar a subjetividade dos professores quando se fala em formação docente. O autor diz, ainda, que na América do Norte e na Europa, os trabalhos que procuram levar em consideração a subjetividade dos professores são desenvolvidos, atualmente, a partir de três grandes orientações teóricas.

De acordo com a primeira orientação teórica, os saberes dos professores são representações mentais a partir das quais os práticos ordenam sua prática e executam suas ações; trata-se, portanto, de saberes procedimentais e instrumentais a partir dos quais o professor elabora uma representação da ação e lhe dá forma. Na segunda, a subjetividade dos professores é vista de maneira muito mais ampla do que na primeira, pois não se limita à cognição ou às representações mentais, mas engloba toda a história de vida dos professores, suas experiências familiares e escolares anteriores, sua afetividade, emoção, crenças, valores etc. Já a terceira, diz que a subjetividade dos professores não se reduz à cognição ou à vivência pessoal, mas remete às categorias, regras e linguagens sociais que estruturam a experiência dos atores nos processos de comunicação e de interação cotidiana.

Assim, para Tardif a profissão docente deveria ser exercida de um modo no qual os professores:

não sejam reconhecidos como sujeitos do conhecimento quando lhes concedermos, dentro do sistema escolar e dos estabelecimentos, o status de verdadeiros atores, e não o de simples técnicos ou de executores das reformas da educação concebidas com base numa lógica burocrática “top and down”. (TARDIF, 2014, p. 243)

No caso da formação de professores pelo Parfor, é considerado que para ser ator de sua ação e autor do seu discurso, o professor precisa ter formação na área de conhecimentos na qual atua, sendo fundamental a participação ativa do profissional docente nesta e em outras políticas de formação, como forma de ter plena capacidade de repensar suas atividades pedagógicas, a partir do conhecimento da área em que atua.

Nesse sentido, os entes da federação, de acordo com A Lei de Diretrizes e Bases da Educação Nacional nº 9394 (BRASIL, 1996), são responsáveis pela formação de professores, tal como apontado no artigo 62 da LDB. 
$\S 1^{\circ}$ A União, o Distrito Federal, os Estados e os Municípios, em regime de colaboração, deverão promover a formação inicial, a continuada e a capacitação dos profissionais de magistério.

$\S 3^{\circ} \mathrm{A}$ formação inicial de profissionais de magistério dará preferência ao ensino presencial, subsidiariamente fazendo uso de recursos e tecnologias de educação a distância.

$\S 4^{\circ} \mathrm{A}$ União, o Distrito Federal, os Estados e os Municípios adotarão mecanismos facilitadores de acesso e permanência em cursos de formação de docentes em nível superior para atuar na Educação Básica pública. (BRASIL, 1996, [p. 35])

Assim, vê-se programas de formação de professores, inicial ou continuada, sendo propostos e subsidiados pelo poder público, em ação conjunta entre a União, Estados, Distrito Federal e os Municípios. Para Ghedin, Leite e Almeida a partir da LDB/1996, houve um movimento que colocou em evidência a importância e complexidade do processo de formação de professores, sendo possível perceber

que novas políticas e novas legislações foram se regulamentando, no âmbito do Governo Federal, por meio do Conselho Nacional de Educação. Essas novas regulamentações foram apresentadas como possibilidades de melhor responder à questão da formação inicial do professor, tentando superar os problemas já encontrados e apontados nas pesquisas acadêmicas e nos problemas decorrentes do cotidiano da sala de aula. (GHEDIN; LEITE; ALMEIDA, 2008, p. 39)

Também Pereira (2006) refere que a formação de professores, sendo tema da LDB de 1996, reforça o papel das licenciaturas como lócus dessa formação, uma vez que:

Essa lei determina que a formação de docentes para a Educação Básica aconteça "em nível superior, em curso de licenciatura, de graduação plena, em universidades e institutos superiores de educação" e admite "como formação mínima para exercício do magistério na educação infantil e nas quatro primeiras séries do ensino fundamental, a oferecida em nível médio, na modalidade Normal”. (A lei prevê também a existência de programas de formação pedagógica para portadores de diplomas de educação superior que queiram se dedicar à Educação Básica). (PEREIRA, 2006, p. 73)

Assim, ressalta-se que, embora o atendimento à formação de professores já fosse uma prática das instituições de ensino superior, especialmente as públicas, com a promulgação da LDB (1996), os cursos de licenciatura se tornaram estratégicos, demandando outras ações, como as reestruturações curriculares e a oferta de outras 
opções para que a formação em nível superior fosse atendida. Souza (2014, p. 631) considera que a lei n. 9.394 definiu os níveis de qualificação para atuação docente na Educação Básica, assim como:

o Plano Nacional de Educação - PNE 2001-2010, lei n. 10.172, que declarou a necessidade de formação dos professores como um dos maiores desafios a serem superados e estabeleceu metas para a ampliação da oferta de cursos de formação, em nível superior, para professores da educação infantil e dos ensinos fundamental e médio. (BRASIL, 2001a apud SOUZA, 2014, p. 631)

Assim como o "atual PNE, lei n. 13.005, de 25 de junho de 2014 (Brasil, 2014), revela preocupação com a qualificação docente para a Educação Básica em duas das vinte metas que o compõem.” (BRASIL, 2014 apud SOUZA, 2014, p. 631).

Para Dourado (2015), na última década, houve um movimento que desencadeou ações direcionadas à formação de profissionais do magistério da Educação Básica, incluindo questões e proposições atinentes à valorização desses profissionais. No âmbito do Conselho Nacional de Educação (CNE), houve ações em busca de maior organicidade para a formação de profissionais do magistério da Educação Básica. Com isso, foi anunciada, em programas e projetos de formação docente, a preocupação política com os desafios da qualificação docente para a Educação Básica, ressaltada por meio de legislação específica, planos nacionais e programas de governos voltados para a educação.

É sabido, entretanto, que o quadro atual da profissionalização docente ainda está muito aquém das demandas por professores habilitados para o exercício da docência em diferentes áreas do conhecimento, tornando imprescindível, não apenas manter políticas públicas voltadas para tal finalidade, como melhorá-las e ampliá-las. Nesse sentido, a criação do programa Parfor visou atender essas demandas promovendo a formação de professores que exercem a docência sem ter formação para a área na qual atuam. 


\section{Aspectos metodológicos}

Entende-se a metodologia da pesquisa em ensino como a produção de conhecimentos resultante da busca de respostas à questão formulada de pesquisa, dentro de um quadro epistemológico, teórico e metodológico consistente e coerente (MOREIRA, 2011). A pesquisa que estamos apresentando está embasada em métodos quantitativos e qualitativos de análise. Sobre pesquisas com enfoque quanti-qualitativo, Moreira (2011) afirma que tais abordagens subscrevem diferentes paradigmas, diferentes visões de mundo, que levam a diferentes maneiras de ver os fenômenos educacionais, de selecionar objetos e eventos para estudar esses fenômenos, de formular questões, de fazer registros, de transformar registros em dados e de analisá-los.

Considerando os diferentes lugares que podem ser ocupados em estudos educacionais, tais fenômenos educacionais envolvem professores (ensino), alunos (aprendizagem), currículos e avaliação (SCHAWAB, 1983, apud GOWIN, 1981; NOVAK e GOWIN, 1996), tornando-se focos de análise nas perspectivas qualitativa e quantitativa à pesquisa em educação.

No estudo sobre o Parfor, a análise qualitativa da pesquisa se utiliza, também, do levantamento e análise dos dados quantitativos, sendo realizada a interpretação qualitativa dos dados numéricos, visando identificar os pontos positivos e negativos do programa de forma a produzir reflexões críticas a respeito do tema, especialmente pela conexão do Parfor com a formação de professores e com o currículo, considerando seu objetivo de formar professores em exercício para as áreas de conhecimento nas quais atuam.

Os aspectos quantitativos foram necessários para o levantamento de informações sobre o Parfor em documentos disponibilizados nos sites da Capes e do Mec, para o conhecimento de gráficos, planilhas, tabelas, quadros e infogramas que indicam os números de cursos, professores, alunos, matrículas e egressos, entre outros dados. $\mathrm{Na}$ sequência, e concomitante a essa abordagem quantitativa, foram realizadas análises qualitativas, em relatórios de gestão DEB/Capes e Relatórios de Prestação de Contas das IES envolvidas, buscando compreender o papel do programa em relação às finalidades e conhecimentos apontados em documentos oficiais do Conselho Nacional de Educação 
(CNE), especialmente as Diretrizes Curriculares Nacionais para a Educação Básica (DCNEB) e as Diretrizes Curriculares Nacionais para a Formação de Professores (DCNFP).

Para a realização da pesquisa, consideramos um recorte na linha do tempo, entre os anos de 2007 a 2016, levando em conta que o Plano Nacional de Formação dos Professores da Educação Básica no âmbito do Ministério da Educação, foi instituído pela Portaria MEC $n^{\circ}$ 09, de 30 de junho de 2009, e em edital com oferta de vagas até o ano de 2016.

No caso deste trabalho de pesquisa, o corpus para a análise foi o banco de dados da Capes, complementado pela pesquisa em artigos, livros, dissertações e teses ${ }^{5}$ e, principalmente, os Relatórios de Gestão DEB/Capes e os Relatórios de Cumprimento do Objeto, disponíveis nos Relatórios de Prestações de Contas de 16 Instituições de Ensino Superior que receberam recursos da Capes para propor cursos de formação de professores.

O critério de seleção para o recorte das IES, cujos relatórios foram analisados, foi o fato de terem oferecido curso de formação na área de Ciências da Natureza: ciências, biologia, química ou física. As IES selecionadas foram: o Instituto Federal do Amazonas (IFAM-AM), Universidade Estadual do Amazonas (UEA-AM), Universidade Federal do Amazonas (UFAM-AM), Universidade Federal do Amapá (UNIFAP-AP), Universidade do Estado da Bahia (UNEB-BA), Instituto Federal do Maranhão (IFMA-MA), Universidade Federal do Pará (UFPA-PA), Universidade Estadual do Piauí (UESPI-PI), Universidade Estadual de Maringá (UEM-PR), Universidade Estadual de Ponta Grossa (UEPG-PR), Universidade Estadual do Norte do Paraná (UENP-PR), Universidade Estadual do Oeste do Paraná (UNIOESTE-PR), Universidade do Oeste de Santa Catarina (UNOESC-SC), Universidade do Sul de Santa Catarina (UNISUL-SC), Pontifícia Universidade Católica de São Paulo (PUC-SP) e a Universidade Federal do Tocantins (UFT-TO).

No caso do Relatório das instituições formadoras, uma das exigências é o preenchimento do Formulário de Cumprimento do Objeto, pela IES, no qual deve estar elencado, entre outros itens, a produção acadêmica dos professores-cursistas e docentes integrantes do programa, tais como: TCC, teses, dissertações, publicações, objetos de

\footnotetext{
5 As teses e dissertações foram extraídas do site oficial da Biblioteca Digital Brasileira de Teses e Dissertações (BDTD), disponível em <http://bdtd.ibict.br/vufind/>. Acesso em: 20 nov. 2017.
} 
aprendizagem, produção cultural, patentes etc., além do envio de anexos de fotos ou outros registros das ações realizadas ao longo do curso. A intenção de analisar os referidos relatórios procurou ver como as IES organizaram os cursos e quais resultados apontaram sobre o aprimoramento da prática docente, sendo esse um dos objetivos do Parfor.

O processo de coleta de dados gerou uma quantidade enorme de informações que precisaram ser organizadas. Tal organização, associando dados quantitativos e qualitativos, reuniu dados que tratavam sobre os aspectos organizacionais de programas de formação de professores pela DEB/Capes, em especial o Parfor, e o papel do programa para o desenvolvimento da articulação teoria-prática da formação apresentada nos relatórios das IES.

\section{Programas de formação de professores no âmbito da DEB/Capes e a implementação do Parfor como programa de formação inicial de professores e como espaço para o desenvolvimento de articulação entre teoria e prática}

A partir da pesquisa no portal da Capes, apresentamos, no Quadro 1, uma síntese dos programas de formação de professores, abrangendo a formação inicial e continuada, no período de 2007 a 2016.

Quadro 1 - Programas de fomento para formação de Professores

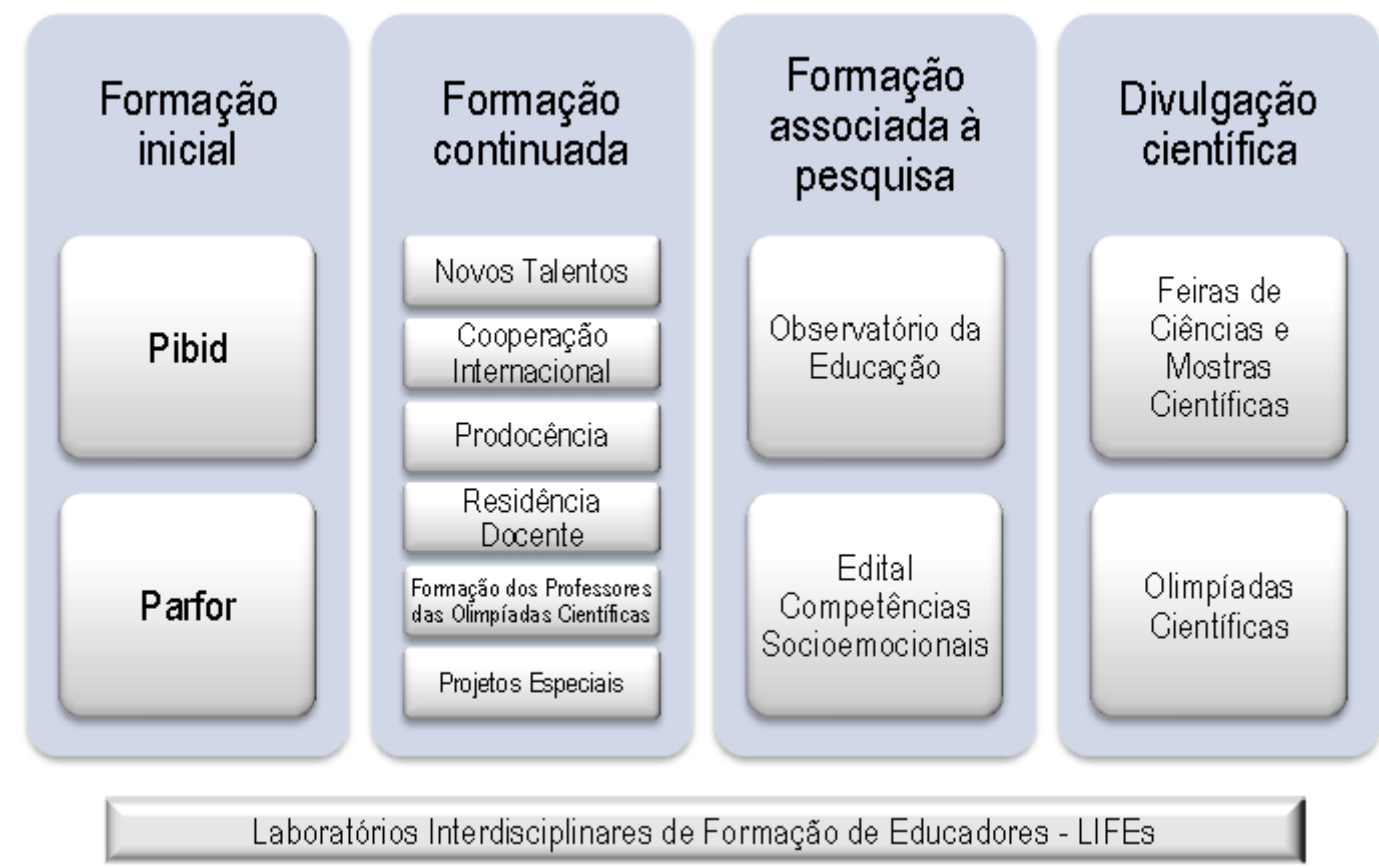

Fonte: Relatório de Gestão DEB/Capes (2009-2014), 2015. 
Uma linha de atuação da DEB/Capes é a formação inicial de professores, uma vez que, de acordo com a Meta 15 do PNE, deve ser assegurada formação específica de nível superior a todos os professores da educação básica, na área de conhecimento em que atuam. Nesse sentido, a Capes desenvolveu dois programas voltados para a formação inicial, conforme quadro acima: o Programa Institucional de Bolsas de Iniciação à Docência (Pibid) e o Plano Nacional de Formação de Professores da Educação Básica (Parfor).

O Pibid, lançado em 2007, é um programa de incentivo e valorização do magistério e de aprimoramento do processo de formação de docentes para a educação básica. O programa oferece bolsas para que alunos de licenciatura exerçam atividades pedagógicas em escolas públicas de educação básica, com a finalidade de contribuir com a integração entre teoria e prática e para a aproximação entre universidades e escolas.

Outro programa de formação inicial de professores, o Parfor, foi lançado em 2009, tendo sido anunciado como uma ação emergencial destinada à formação de professores em serviço. A finalidade do Parfor foi atender à Política Nacional de Formação de Profissionais do Magistério da Educação, instituída pelo Decreto $n^{\circ}$ 6.755/2009, cujas diretrizes estão ancoradas no Plano de Metas Compromisso Todos pela Educação, criado pelo Decreto $n^{\circ}$ 6.094/2007. Como programa estratégico do Plano de Desenvolvimento da Educação - PDE, elencou entre seus objetivos a formação de professores e a valorização dos profissionais da educação.

A segunda linha de atuação da DEB/Capes é o fomento à formação continuada de professores. No período de 2007 a 2016, recorte de tempo desta pesquisa, seis programas foram implementados com essa finalidade: (1) Programa Novos Talentos; (2) Programa de Consolidação das Licenciaturas (Prodocência); (3) Cooperação Internacional para Professores da Educação Básica: o Programa de Desenvolvimento Profissional para Professores (PDPP); (4) Programa Residência Docente'; (5) Formação dos Professores das Olimpíadas de Matemática e Química e (6) Projetos Especiais de Apoio à Educação Básica.

\footnotetext{
${ }^{6}$ Atualmente intitulado Programa de Residência Pedagógica, lançado em 2018, é uma das ações que integram a Política Nacional de Formação de Professores e tem por objetivo induzir o aperfeiçoamento do estágio curricular supervisionado nos cursos de licenciatura, promovendo a imersão do licenciando na escola de educação básica, a partir da segunda metade de seu curso.
} 
A terceira linha de atuação da DEB/Capes, contempla a Formação associada à pesquisa, composta por dois programas: o Observatório da Educação (Obeduc) e o Programa de Apoio à Formação de Profissionais no Campo das Competências Socioemocionais (CSE).

A quarta linha de atuação da DEB/Capes é a Divulgação Científica, composta por Feiras de Ciências, Mostras Científicas e Olimpíadas Científicas. Desde 2011, em parceria com o Conselho Nacional de Desenvolvimento Científico e Tecnológico - CNPq, a Capes induz e fomenta a realização desses programas, que podem ter âmbito nacional, estadual ou municipal.

Também como ação da DEB/Capes, houve a implantação do Programa Laboratórios Interdisciplinares de Formação de Educadores (Life), lançado no segundo semestre de 2012. A implantação do Programa visou atender à necessidade de ampliar o acesso dos cursos de formação docente aos modernos recursos tecnológicos e de inovação educacional.

Mas voltando aos programas de formação inicial fomentados pela DEB/Capes, o Pibid e o Parfor, juntamente à Universidade Aberta do Brasil, são programas que envolvem/envolveram um número grande de professores, sendo representativos do papel da Capes na formação de professores para a Educação Básica, em nível de graduação, na área de conhecimento em que atuam, de modo a atender a Meta 15 do PNE (2014-2024).

O Parfor, criado em 28 de maio de 2009, como já dito, foi apresentado como programa emergencial para atender a formação de professores em diferentes regiões do Brasil, sendo seu objetivo, induzir e fomentar a oferta de educação superior, gratuita e de qualidade, para professores em exercício na rede pública de Educação Básica que não tivessem formação na área de conhecimento em que atuavam, possibilitando a esses profissionais obter a formação exigida pela LDB e contribuir para a melhoria da qualidade da Educação Básica no País (BRASIL, 2009a).

De acordo com o Relatório de Gestão da DEB/Capes (2009-2014), a implementação do Parfor contou com a Plataforma Freire, um sistema criado pelo MEC para realizar a gestão e acompanhamento de cursos ofertados no âmbito da Política Nacional de 
Formação dos Profissionais da Educação Básica (Decreto n 6.755/2009), na qual foi implantado o calendário de organização do fluxo de atividades a serem desenvolvidas pelos parceiros na oferta de cursos do Parfor. Com o uso da Plataforma foi possível: concretizar a participação das secretarias municipais de educação; tornar o ambiente mais acessível aos usuários; facilitar o processo de elaboração do planejamento estratégico pelos Fóruns Estaduais e fortalecer seu papel como articuladores da política de formação docente; e realizar o acompanhamento da demanda, da oferta e das matrículas do Parfor, com a pré-inscrição vinculada ao cadastro no Educacenso e pela integração da Plataforma Freire com o sistema e-MEC.

Isso tudo visando garantir que as turmas especiais ofertadas fossem criadas em cursos de Licenciatura em instituições formadoras, credenciadas no Sistema de Regulação do Ensino Superior/e-MEC7 e autorizadas e ativas para oferta de vagas em cursos que estivessem vinculados ao Índice Geral de Cursos (IGC) ${ }^{8}$ da IES, cujo conceito preliminar de curso (CPC), pela avaliação do INEP, fosse igual ou superior a 3.

De acordo com Relatório de Gestão da DEB/Capes (2009-2014), as ações de aprimoramento da Plataforma Freire e do Sistema de Gestão de Bolsas contribuem para o desenvolvimento, gestão e accountability ${ }^{9}$ do Parfor, sendo implantado, a partir de 2012, um Manual Operativo contendo as normas e um cronograma contendo prazos para a inserção da demanda pelas secretarias de educação e da oferta pelas IES, a homologação do quadro de oferta de cursos e vagas pelos Fóruns, os períodos de pré-inscrição, de seleção e matrícula e de repasse de recursos às IES.

A partir de 2013, passou a haver apenas uma chamada anual para a oferta em cursos presenciais, e, buscando atender as orientações do Decreto $n^{\circ} 7.568$, de 16 de setembro de 2011, a DEB lançou o Edital 30/2013, de 29 de julho de 2013, para a seleção de Instituições Privadas, sem fins lucrativos, que desejassem participar do Parfor, havendo o

\footnotetext{
7 As IES do sistema estadual e municipal, cujo curso não estivesse cadastrado no e-MEC, poderiam participar, mediante apresentação do documento de autorização do curso pelo órgão estadual credenciado para tal fim.

${ }^{8} \mathrm{O}$ Índice Geral de Cursos Avaliados da Instituição (IGC) é um indicador de qualidade que avalia as Instituições de Educação Superior no Brasil.

9 Accountability é um termo da língua inglesa que pode ser traduzido para o português como responsabilidade com ética e remete à obrigação, à transparência, de membros de um órgão administrativo ou representativo de prestar contas a instâncias controladoras ou a seus representados.
} 
envio de propostas de 32 instituições, que foram aprovadas e passaram a ofertar turmas especiais no Programa, mediante participação efetivada por meio de assinatura de Termo de Adesão ao Acordo de Cooperação Técnica (ACT). Com o ingresso de novas IES públicas e privadas, a oferta de cursos nas mais variadas áreas de conhecimento, o número de IES participantes passou de 32, em 2009, para mais de 100, em 2016.

Com relação à participação dos professores no programa, esta é viabilizada por Acordos de Cooperação Técnica (ACT) firmados entre a Capes e as Secretarias Estaduais de Educação ou órgão equivalente, com concessão de recursos de custeio e de bolsas, sendo esses recursos repassados pela Capes para as IES e estas, posteriormente, repassavam esses créditos para os alunos e, também, para os participantes que desempenhassem atividades de coordenação e docência no programa.

Para concorrer à vaga nos cursos ofertados, os professores deveriam: a) realizar seu cadastro e pré-inscrição na Plataforma Freire; b) estar cadastrados no Educacenso na função Docente ou Tradutor Intérprete de Libras na rede pública de Educação Básica; e c) ter sua pré-inscrição validada pela Secretaria de educação ou órgão equivalente a que estiver vinculado.

Com relação aos recursos e investimentos, o montante passou de um pouco mais de 12 milhões, em 2009, para quase 75 milhões, em 2016, mas com períodos de maior aumento de investimentos entre 2011 e 2015. O investimento total foi cerca de 858 milhões, conforme apresentado na Tabela que segue.

Tabela 1 - Financiamento de turmas especiais presenciais do Parfor - 2009 a 2016

\begin{tabular}{c|r} 
Ano & \multicolumn{1}{|c}{ Totais $(\mathbf{R} \mathbf{)}$} \\
\hline 2009 & $12.394 \cdot 341,09$ \\
\hline 2010 & $70.914 .408,33$ \\
\hline 2011 & $110.987 .220,82$ \\
\hline 2012 & $162.895 .436,02$ \\
\hline 2013 & $171.919 .765,09$ \\
\hline 2014 & $152.024 .976,91$ \\
\hline 2015 & $101.779 .600,00$ \\
\hline 2016 & $74.796 .00,00$ \\
\hline Total & $857.711,748,26$
\end{tabular}

Fonte: Sistema de Gestão de Bolsas, 2019. 
Em 2016, em função da crise política que assolou o Brasil, houve uma queda considerável nos valores dos financiamentos do governo, na área de educação, incluindo os programas da Capes voltados para formação inicial e continuada de professores. Esse declínio no fomento à educação entra em contradição com as prioridades da administração pública federal, estabelecidas no Plano Plurianual (PPA), para o período 2016-2019, conforme Lei $n^{\circ}$ 13.249, de 13 de janeiro de 2016, a saber:

Art. 30 São prioridades da administração pública federal para o período 2016- 2019:

I - as metas inscritas no Plano Nacional de Educação (Lei n 13.005, de 25 de junho de 2014);

II - o Programa de Aceleração do Crescimento - PAC, identificado nas leis orçamentárias anuais por meio de atributo específico; e

III - o Plano Brasil sem Miséria - PBSM, identificado nas leis orçamentárias anuais por meio de atributo específico. (BRASIL, 2016, art. 3.)

Uma prioridade estabelecida no PPA (2016-2019) seria atingir as metas inscritas no PNE (2014), produzindo uma educação de qualidade, no entanto, após o impeachment da presidente da república Dilma Rousseff, em 2016, o Governo do Presidente Michel Temer alterou o Plano de Governo que vinha sendo desenvolvido, promovendo cortes em vários programas públicos de fomento à educação no Brasil, sendo que no ano de 2016, em comparação com 2015, houve um corte nos investimentos de $\mathrm{R} \$$ 26.983.600,00, conforme apontado na Tabela 1.

Os princípios pedagógicos do Parfor se baseiam no direito de aprender de crianças e jovens, extensivo a seus professores, considerando que a educação seja estabelecida em bases sólidas (científicas e técnicas) e em um projeto social, político e ético que contribua para a consolidação de uma nação soberana, democrática, justa e inclusiva. Esses princípios deveriam estar articulados aos princípios orientadores para o planejamento pedagógico dos cursos pelas IES, prevendo a articulação entre teoria e prática em todo o percurso formativo; a garantia do domínio de conhecimentos científicos e didáticos; a indissociabilidade entre ensino, pesquisa e extensão e o reconhecimento da escola como espaço necessário à formação inicial dos profissionais do magistério. 
Assim, aos princípios e objetivos da Política Nacional de Formação de Profissionais do Magistério da Educação Básica (2009-2014), incluíam-se os objetivos específicos do Parfor $^{10}:$ a) promover o acesso dos professores em exercício na rede pública de Educação Básica à formação superior exigida pela LDB; b) consolidar os Fóruns Estaduais Permanentes de Apoio à Formação Docente (Fepad), nos termos do Decreto $\mathrm{n}^{\circ}$ 6.755/2009, como instância de debate, planejamento e organização, que analisam a demanda das redes (estadual e municipal) e acompanham o desenvolvimento da formação docente em cada unidade da federação; c) fomentar a articulação entre Educação Básica e educação superior, inclusive entre a pós-graduação, as IES e a escola básica; d) despertar o interesse dos professores formadores para a realização de estudos e pesquisas sobre formação docente, utilizando as vivências e as trocas de experiência e saberes advindos do estreito contato desses formadores com docentes em pleno exercício; e e) elevar a qualidade da formação docente nas escolas de Educação Básica.

Quando de sua criação, a oferta de turmas do Parfor ocorreu nas modalidades presencial e a distância, em regime de colaboração entre a Capes, os estados, municípios, o Distrito Federal e as IES, mas a partir de 2012, a Capes passou a ofertar apenas cursos na modalidade presencial. A proposta inicial de formação se caracterizou pela formação de professores em serviço, que não tinham formação na área em que atuavam, organizada nas seguintes situações ${ }^{11}$ :

I. Licenciatura - para docentes ou tradutores intérpretes de Libras em exercício na rede pública da Educação Básica que não tenham formação superior ou que mesmo tendo essa formação se disponham a realizar curso de licenciatura na etapa/disciplina em que atuam em sala de aula;

II. Segunda licenciatura - para professores que estejam em exercício há pelo menos três anos na rede pública de Educação Básica e que atuem em área distinta da sua formação inicial, ou para profissionais licenciados que atuam como tradutor intérprete de Libras na rede pública de Educação Básica; e

\footnotetext{
10 Disponível em: <https://www.capes.gov.br/images/stories/download/legislacao/Decreto-6755-2009.pdf>. Acesso em: 30 out. 2018.

11 Disponível em: <https://www.capes.gov.br/images/stories/download/legislacao/2782014-MANUALOPERATIVO-PARFOR.pdf>. Acesso em: 15 jan. 2018.
} 
III. Formação pedagógica - para docentes ou tradutores intérpretes de Libras graduados não licenciados que se encontram no exercício da docência na rede pública da Educação Básica.

Sendo o Parfor um programa desenvolvido com o intuito de estar em consonância com as orientações do PNE (2014-2024), cabe lembrar que algumas diretrizes desse documento legal são a melhoria da qualidade da educação e a valorização dos profissionais da educação. Então, poderíamos nos perguntar, de que modo o programa teria contribuído para o alcance dessas diretrizes? Teria o Parfor um papel de relevância na condução de estratégias para ampliar a oferta de cursos de formação inicial e continuada de professores e assegurar formação específica na educação superior, valorizando a experiência prática?

Com dados quantitativos trazidos neste texto, podemos mostrar alguns resultados e tecer reflexões sobre esses questionamentos. Mas antes, vale a reflexão sobre a relevância do papel das instituições de ensino superior no processo de desenvolvimento educacional do país.

Não se pode falar da gestão das instituições de ensino superior de um país sem antes falar do que se espera desse conjunto de instituições. Em geral, o mais comum, e o que ocorre nos países que conseguiram elevados índices de desenvolvimento material e tecnológico, é esperar que essas instituições e, dentre elas, principalmente aquelas qualificadas como universidades, possam contribuir para o país enfrentar com êxito os desafios presentes na sociedade, tanto no que diz respeito ao desenvolvimento social, econômico e cultural, quanto à contribuição para assegurar a competitividade técnica da economia nacional, no contexto internacional. (BERCHEM, 1990, p. 9)

Os autores chamam a atenção para o papel das instituições de ensino superior, quanto ao desenvolvimento social, econômico e cultural do país. Cabe lembrar que elas exercem um papel importante no processo de formação de professores, de modo geral, e, em especial, em um programa emergencial como o Parfor.

Sendo o Parfor destinado a professores em exercício que não possuem a formação na área que atuam, as turmas especiais foram compostas por alunos que comprovaram estar no exercício da docência na rede pública, na área ou na disciplina de atuação, mas que não tinham formação em curso de licenciatura. A participação do 
professor nos cursos de formação foi autorizada pelo secretário de educação ou órgão equivalente, atestando que o professor atendia os requisitos do Programa.

Sendo assim, foi possível identificar por meio dos relatórios das IES que o Programa Parfor teve um papel importante na correção do problema de professores que não possuíam a formação específica na área em que atuavam como docentes. É possível chegar a essa conclusão, tanto pelo volume de recursos investidos, conforme visto na Tabela 1, quanto pelo número de professores que aderiram ao programa, conforme será visto no Quadro 2, logo em seguida.

Como visto na Tabela 1, a partir de 2016, houve diminuição de recursos para o programa Parfor, assim como em outros programas da Capes, comprometendo a viabilização dos projetos em áreas prioritárias, como é o caso da educação básica. Mesmo com o corte de verbas, o Parfor continuou atendendo, em 2016, um contingente grande de alunos, especialmente nas regiões norte e nordeste, conforme mostrado no Quadro $2^{12}$.

Quadro 2 - Parfor: Números de alunos por região em 2016

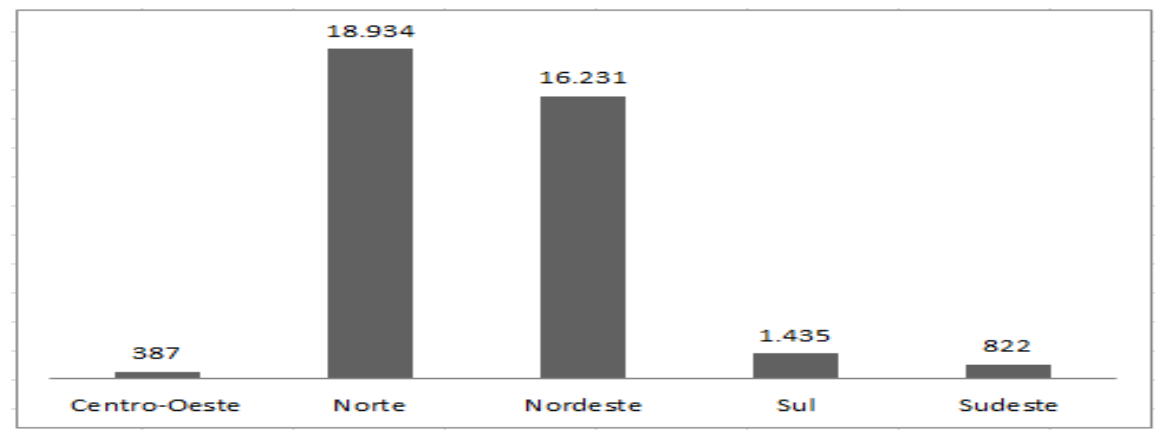

Fonte: Plataforma Freire (2017).

O número maior de alunos da região norte e nordeste pode ser explicado pela maior demanda para a formação de professores da educação básica nestas regiões. A Lei de Diretrizes e Bases, nas Disposições Gerais, especificamente no artigo 28, aponta ser necessário considerar as especificidades de cada região, ao afirmar que os sistemas de

\footnotetext{
12 Destaca-se que em 2017 a dotação orçamentária inicial recebida pela Capes, para o fomento da educação

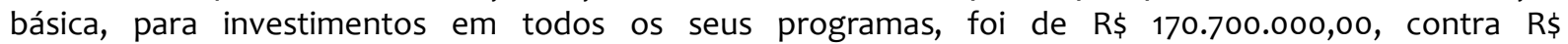
197.066.041,00, no ano de 2016. Uma redução de pouco mais de 26 milhões de reais. Disponível em <http://www.capes.gov.br/images/stories/download/diversos/02052017-ORCAMENTO-POR-PPA-20042019.pdf>. Acesso em: 21 mar. 2018.
} 
ensino promoverão as adaptações necessárias para a adequação da educação básica às peculiaridades da vida rural e de cada região.

Quanto aos efeitos do Parfor no atendimento à demanda de formação pelos professores, o Relatório de Gestão DEB/Capes (2009-2014) aponta a contribuição do Programa em oportunizar formação superior aos professores em serviço, já apontado pelo Relatório de Avaliação do Parfor presencial e a distância, elaborado pela Prof. ${ }^{a}$ Dr. ${ }^{a}$ Bernardete A. Gatti (2011) ${ }^{13}$. Tal relatório destaca:

Um esforço reconhecível por parte das instituições em realizar um trabalho adequado, tanto no programa Parfor, como nos cursos oferecidos a distância dentro da proposta UAB. (...). Constata-se esforço e engajamento, tanto institucional como na implementação dos currículos, na direção de atingir profissionais e estudantes que teriam dificuldades de diversas ordens em realizar sua formação em nível superior não fossem essas modalidades de oferta. (GATTI, 2011, p. 60)

Conforme apontamentos nos Relatórios de Prestação de Contas das 16 IES selecionadas, quanto ao Parfor, as atividades foram desenvolvidas de acordo com o modelo tradicional de ensino, ou seja, havia a presença de um professor na sala de aula ministrando o conteúdo aos professores que não possuíam a formação na área adequada à qual lecionavam. Quanto aos cursos oferecidos a distância, ressalta-se que o Governo Federal implementou o Programa UAB (Universidade Aberta do Brasil), no qual foram construídos Polos de Formação nas regiões do Brasil, onde não havia universidades. Com essa ação foi possível implementar a interiorização da educação, ou seja, possibilitou a aproximação entre as universidades e os alunos. Dessa forma, aquele estudante que morava em alguma cidade do interior, em local onde não havia uma IES nas proximidades, não precisaria mais se deslocar para alguma capital, com a finalidade de realizar os seus estudos.

O relatório aponta, ainda, que as previsões de aposentadorias e o déficit de professores, em especial nas áreas de Matemática, Física, Química e Biologia, reforçam a necessidade de incremento a políticas e programas de formação docente. Assim, nesse

13 Projeto de Cooperação Técnica MEC/UNESCO “Fortalecimento das Políticas de Valorização e Profissionalização Docente" (n 914BRZ1127), realizado por um grupo de especialistas orientados pela pesquisadora Bernardete Gatti. 
contexto, é sinalizada a importância do Parfor. Os dados dos relatórios mostram que as ações de formação de professores do Parfor ampliaram as oportunidades de acesso à educação superior dos docentes em serviço, especialmente nos municípios do interior das regiões norte e nordeste do País.

Assim, o Parfor se apresenta em consonância com as diretrizes curriculares para a formação de professores e com pesquisas e estudos contemporâneos em educação, que valorizam a formação de professores em serviço, cujos saberes estão associados à prática, de modo a haver articulação entre teoria e prática. Alves e Garcia, no que tange a essa relação na profissão docente, tecem as seguintes considerações:

Rompendo com a histórica segmentação e hierarquização entre teoria e prática, em que o momento da teoria precedia o momento da prática, que se dava apenas através dos estágios, entendeu-se que a pesquisa, percorrendo todo o curso, garantiria uma permanente relação teoriaprática. Prática não entendida apenas como atividade, mas também e, principalmente, como acumulação e transmissão de conhecimentos apriorísticos, vistos como apropriação refletida da prática. (ALVES; GARCIA, 2008, p. 79-80)

Alves (1986 apud ALVES; GARCIA, 2008, p. 79-80), afirma que “[...] não se pode pensar a formação simplesmente na esfera acadêmica", no entanto.

[...] é preciso pensá-la na totalidade das esferas que a compõem: a da prática pedagógica cotidiana, a da prática política coletiva, a da ação governamental e a das pesquisas em educação. (ALVES; GARCIA, 2008, p. 79-80)

Assim, as autoras chamam a atenção para a amplitude da prática em várias dimensões; não apenas no sentido de realização de atividade, mas, também, considerando o processo de reflexão sobre o exercício profissional e os aspectos envolvidos nas direções horizontal e vertical. No sentido horizontal, dizem ser salutar considerar, além dos professores e alunos envolvidos no processo de aprendizagem, toda a equipe técnico-pedagógica, coordenações etc. Na acepção vertical, referem a importância de considerar todos os níveis de formação do aluno, desde o nível básico à pós-graduação stricto sensu. 
No caso da formação pelo Parfor, conforme os dados que constam nos relatórios de prestação de contas de 16 Instituições de Ensino Superior, da área de Ciências de Natureza, a partir da análise do Relatório de Cumprimento de Objeto ${ }^{14}$ das IES, foram encontradas as seguintes atividades voltadas para a prática docente: aulas de campo, aulas práticas, estágio supervisionado relacionando à teoria com a práticas, trabalhos de conclusão de curso, dissertações e teses voltados para a temática da prática docente, semanas pedagógicas, mostras de experiência e extensão, e atividades integradoras (correspondentes às atividades complementares), com o objetivo de aprimorar as atividades docentes, levando os alunos à reflexão de sua prática e das políticas educacionais. O levantamento de atividades realizadas nos cursos indica que as IES tiveram a preocupação em dar sustentação teórica à prática docente.

Os professores-alunos do programa, no cotidiano do trabalho, estão em busca de informações, conhecimentos e formam-se na prática, vivenciando e partilhando suas experiências docentes. Nesse sentido, é necessário investir em propostas de formação em serviço que mobilizem os professores na reconstrução de alternativas coerentes com os pressupostos teóricos da concepção formativa. Isso significa garantir uma formação mais ampla e de qualidade para esses profissionais.

Tardif (2014, p. 234-235) aponta algumas considerações envolvendo possíveis conexões entre teoria e prática docente ao afirmar que sendo os professores sujeitos competentes e ativos, suas práticas não são somente um espaço de aplicação de saberes provenientes da teoria, mas também um espaço de produção de saberes específicos oriundos dessa mesma prática. Para esse autor,

O trabalho dos professores de profissão deve ser considerado como um espaço prático específico de produção, de transformação e de mobilização de saberes e, portanto, de teorias, de conhecimentos e de saber-fazer específicos ao ofício de professor. Essa perspectiva equivale a fazer do professor (...) um sujeito do conhecimento, um ator que desenvolve e possui sempre teorias, conhecimentos e saberes de sua própria ação. (TARDIF, 2014, p. 234-235)

\footnotetext{
14 De acordo com o Manual Operativo do Parfor, as Instituições Federais de Educação Superior que firmam Termo de Cooperação com a Capes devem apresentar até o dia 31 de janeiro de cada exercício o relatório de cumprimento de objeto, para fins de prestação de contas.
} 
Ou seja, o exercício da prática docente contribuiria para o processo de reflexão das atividades realizadas, em um movimento da prática repensando a prática. Ressalta-se que a articulação entre teoria e prática em todo o percurso formativo está dentre os princípios pedagógicos e objetivos do Parfor no que tange a formação de professores, além da garantia do domínio de conhecimentos científicos e didáticos; da indissociabilidade entre ensino, pesquisa e extensão e do reconhecimento da escola como espaço necessário à formação inicial dos profissionais do magistério.

Mas de que forma esses princípios contemplados no Parfor foram atendidos pelo que consta nos relatórios das IES? De acordo com as observações, a garantia do domínio de conhecimentos científicos e didáticos foi buscada por meio dos cursos, que contemplavam as áreas da formação específica, à qual os professores lecionavam e não possuíam a formação adequada. Quanto à indissociabilidade entre ensino, pesquisa e extensão, ressalta-se que as IES buscaram atingir esse objetivo por meio das aulas ministradas aos alunos, que consequentemente, aplicaram seus conhecimentos na produção de trabalhos de pesquisa, especialmente, aqueles voltados para a identificação de problemas relacionados à sociedade a qual estão inseridos.

Já o reconhecimento da escola como espaço necessário à formação inicial dos profissionais do magistério, ao fomentar atividades como aulas de campo, aulas práticas e estágio supervisionado com atividades práticas, conforme constam nos relatórios de prestações de contas das IES, o Parfor, de certa forma, contribui para a conexão entre teoria e prática.

Assim, ao tratar a formação de professores e sua prática docente, há que se considerar a importância em disponibilizar aos profissionais docentes, a infraestrutura física de suporte, de forma que esses profissionais tenham as condições básicas necessárias para desenvolverem suas atividades. Ghedin, Almeida e Leite, alegam que:

Para que a escola seja capaz de encaminhar essa reestruturação, muitos aspectos se colocam como pré-requisito: as condições de infraestrutura, de trabalho, de salário e carreira docente, o número de alunos por sala e de professores na escola, o apoio técnico-pedagógico ao ensino, mas principalmente a compreensão dos professores sobre seu trabalho, sobre a escola e sobre seus alunos, o que deveria estruturar-se por meio de um sólido programa de formação continuada capaz de mobilizar os profissionais na direção de construírem outras concepções a respeito do 
processo de ensino-aprendizagem e das concepções sobre o papel da escola. (ALMEIDA; LEITE, 2008, p. 98)

Freitas, ao discutir a prática pedagógica e sua supervalorização em relação à formação acadêmica dos docentes, ressalta que, atualmente,

A formação do professor é preferencialmente vista como algo prático. O conceito de "prática social" tende a ser reduzido ao conceito de "problemas concretos", e os últimos orientam a formação do educador. Com isso, a formação teórica do educador corre sérios riscos. É importante salientar que muitos de nós colaboramos com esta visão, quando simplesmente propomos uma inversão de ênfase no currículo de formação do professor, defendendo o predomínio da "prática". Em nossa opinião, não se trata de inverter o estado atual - mais teoria, pouca prática - para outro que se caracterize por muita prática e pouca teoria. O V Encontro Nacional da ANFOPE, em 1990, deixou claro a importância de uma formação teórica de qualidade para o educador. No cenário brasileiro e na fala de alguns pesquisadores, já se pode começar a notar a presença dessas propostas que querem colocar a formação teórica do professor na dependência dos problemas práticos que ele enfrenta em seu dia-a-dia, também chamado de cotidiano. (FREITAS, 2008, p. 95-96)

Para a autora, com isso, elimina-se a formação teórica (e política) do profissional, convertendo-o em um 'practitioner' (um prático), (FREITAS, 2008, p. 95), sendo que a questão não seria aumentar a prática em detrimento da teoria, mas em "adotarmos uma nova forma de produzir conhecimento no interior dos cursos de formação do educador" (FREITAS, 2008, p. 95-96). Ela atenta para uma questão que é quase um contraponto ao que foi dito anteriormente pelas autoras Alves e Garcia sobre a importância da prática pedagógica. Mas é importante destacar que a autora não defende mais teoria em detrimento da prática e nem o oposto; ele alega que é necessário levar em conta novas formas de produção de conhecimento no interior dos cursos de formação dos profissionais docentes. E isso deve ser pensado em relação aos cursos de formação em geral, inclusive cursos de formação em rede como é o caso do Parfor, sendo essa relação entre teoria e prática uma dimensão importante de ser investigada, como foi o caso deste trabalho de pesquisa, conforme apontamentos anteriores. 


\section{Considerações finais}

O trabalho desenvolvido neste artigo visou apresentar os programas de formação de professores fomentados pela Capes, em especial, o Parfor, investigando as atividades desenvolvidas pelas IES para fomentar a prática docente. A Política Nacional de Formação de Professores da Educação Básica objetivou equalizar nacionalmente as oportunidades de formação inicial e continuada dos profissionais do magistério, procurando assegurar a todos os professores em efetivo exercício, sem curso superior ou que atuam fora da sua área de formação, que tivessem acesso a essa formação.

Nesse contexto, embora o Parfor tenha sido criado em um caráter emergencial para ampliar o acesso dos professores em exercício à formação inicial, observa-se que suas ações foram um espaço de produção de conhecimento e inovação educacional e, principalmente, uma estratégia de atualização e preparação dos professores da Educação Básica para atuarem na escola e no mundo complexo do século atual (Relatório de Gestão DEB/ Capes 2009-2014). Assim, pode-se dizer que o programa viabilizou e proporcionou possibilidades ao Ministério da Educação de encontrar novos paradigmas para as políticas de formação docente no Brasil.

Percebe-se no decorrer deste trabalho de pesquisa, por meio da análise efetuada nos relatórios de prestação de contas das 16 IES selecionadas, o comprometimento das Instituições de Ensino Superior na execução do Programa Parfor, em adotar atividades voltadas para o aprimoramento da prática docente, em uma tentativa de cumprir os ditames da relação teoria-prática, conforme mencionada ao longo desta pesquisa.

Finalizando, destacamos que o quadro político de instabilidade com relação às políticas para a formação de professores e para a educação de modo geral, instaurada no país a partir de 2015, e de forma mais contundente em 2016, provocou a descontinuidade do Parfor, que será substituído pelo Programa de Formação Inicial e Continuada para Professores da Educação Básica (Profic).

Segundo a Diretoria de Educação Básica da Capes, a implementação do Profic visaria atualizar o Parfor, com mudanças anunciadas no método de repasse (recursos financeiros seriam repassados diretamente às instituições) e nos currículos dos cursos, 
sendo os programas do Parfor e do Profic concomitantes, até a conclusão da última turma do Parfor.

\section{Referências}

ALMEIDA, Malu. Políticas educacionais e práticas pedagógicas para além da mercadorização do conhecimento. Campinas, São Paulo: Alínea, 2005.

ALVES, Nilda; GARCIA, Regina Leite. A construção do conhecimento e o currículo dos cursos de formação de professores na vivência de um processo. In: ALVES, Nilda (Org.). Formação de professores, pensar e fazer. 10 ed. São Paulo, Cortez, 2008. (Coleção Questões da Nossa Época; v. 1). P. 79-80.

BERCHEM, Theodor. A missão das universidades na formação e no desenvolvimento culturais: a diversidade dentro da universalidade. In: CADERNOS PLURAIS: A missão da universidade hoje. Rio de Janeiro: Gráfica da UERJ, 1990. (série Universidade-I, v. 5).

BRASIL. Decreto n. 6.094, de 24 de abril de 2007. Dispõe sobre a implementação do plano de metas compromisso todos pela educação (compromisso). Diário Oficial da União, Brasília, DF, 25 abr. 2007. Disponível em: http://www.planalto.gov.br/ccivil_03/_ato20072010/2007/decreto/d6094.htm. Acesso em: 16 jun. 2014.

BRASIL. Decreto n. 6.755, de 29 de janeiro de 2009. Institui a política nacional de formação de profissionais do magistério da educação básica, disciplina a atuação da capes no fomento a programas de formação inicial e continuada e dá outras providências. Diário Oficial da União, Brasília, DF, 30 jan. 2009a. Disponível em: http://www.planalto.gov.br/ccivil_03/_ato2007-2010/2009/decreto/d6755.htm. Acesso em: 16 jun. 2010.

BRASIL. Lei n. 9.394, de 20 de dezembro de 1996. Institui as diretrizes e bases da educação nacional. Diário Oficial da União, Brasília, DF, 23 dez. 1996. Disponível em: http://www.planalto.gov.br/ccivil_03/leis/l9394.htm. Acesso em: 16 jun. 2010.

DOURADO, Luiz Fernandes. Diretrizes curriculares nacionais para a formação inicial e continuada dos profissionais do magistério da educação básica: concepções e desafios. Educ. Soc., Campinas, v. 36, n. 131, abr./jun., p. 299-324, 2015. Disponível em http://www.scielo.br/pdf/es/v36n131/1678-4626-es-36-131-00299.pdf. Acesso em: 25 ago. 2016. 
FREITAS, Luiz Carlos de. Neotecnicismo e formação do educador. In: ALVES, Nilda (org.). Formação de professores, pensar e fazer. 10 ed. São Paulo, Cortez, 2008. p. 95-96. (Coleção Questões da Nossa Época; v. 1).

GATTI, Bernardete Angelina.; BARRETO, Elba Siqueira De Sá.; ANDRÉ, Marli Eliza Dalmazo De Afonso. Políticas docentes no Brasil: um estado da arte. Brasília: UNESCO, 2011. GHEDIN, Evandro; ALMEIDA, Maria Isabel; LEITE, Yoshie Ussami Ferrar. Formação de professores, caminhos e descaminhos da prática. Brasília: Líber Livro Editora, 2008. p. 3032.

GOWIN, D. Bob. (1981). Educating. Ithaca, N.Y., Cornell University Press. 210p.

MOREIRA, M. A. Metodologias de pesquisa em ensino. 1. ed. São Paulo: Livraria da Física, 2011.

NOVAK, Joseph D. e GOWIN, D Bob. (1996). Aprender a aprender. Lisboa. Plátano Edições Técnicas. Tradução ao português, de Carla Valadares, do original Learning how to learn. 212p.

PEREIRA, Júlio Emílio Diniz. Formação de professores: pesquisas, representações e poder. Minas Gerais: Autêntica, 2006.

SOUZA, Valdinei Costa. Política de formação de professores para a educação básica, a questão da igualdade. Revista Brasileira de Educação, Rio de Janeiro, v. 19 n. 58 jul./set. 2014.

TARDIF, Maurice. Saberes docentes e formação profissional. 17. ed. Petrópolis, RJ: Vozes, 2014. p. 229-230.

Recebido em: 25/04/2018 Revisões requeridas: $23 / 07 / 2018$ Aprovado em: 01/10/2018

Universidade do Estado de Santa Catarina - UDESC Programa de Pós-Graduação em Educação - PPGE Revista Linhas Volume 21 - Número 46 - Ano 2020 revistalinhas@gmail.com 